\title{
História científica, história contemporânea e história cotidiana
}

Norberto Luiz Guarinello Depto. de História/USP

\section{RESUMO}

Este artigo discute alguns dos impasses da História contemporânea, identificando alguns de seus limites como disciplina científica e ressaltando sua especificidade frente às demais ciências humanas. A partir da perspectiva do tempo cotidiano, discute conceitos como tempo histórico, estrutura e ação.

Palavras-Chave: História; Historiografia; Cotidiano; Estrutura; Ação.

\begin{abstract}
This paper discusses several of deadlocks confronted by contemporary historiography. It tries to assert both its limitations as a science and its special contribution to the Social Sciences in general. From an everyday life point of view it discusses historical time, structure and action.
\end{abstract}

Keywords: History; Historiography; Everyday Life; Structure; Action.

\section{INTRODUÇÃO}

O objetivo deste artigo é fazer um breve e esquemático balanço dos desafios colocados pela história contemporânea à ciência da História ${ }^{1}$ e propor alguns caminhos de reflexão. Caminhos que, como se verá, limitam-se a buscar alternativas possíveis, mais que a propor soluções ou respostas positivas a questões específicas. A História, como gênero específico dentro da tradição literária européia, ou enquanto disciplina científica, possui uma longa história que seria impossível, e mesmo inútil, tentar sintetizar neste espaço. Em termos bem gerais, no entanto, pode-se considerar que, como forma de memória pública, sempre exerceu certo efeito tranqüilizador para a eternamente instável relação das sociedades humanas com o tempo, mesmo quando assumiu o papel de crítica do presente. A História, como trabalho de rememoração ou de explicação do passado, permitia prever tempos futuros, seja pela repetição ou emulação do ocorrido, seja pela projeção causal de um desenvolvimento desejado e possível. Em outras palavras, um certo desejo de segurança em relação ao futuro (como repetição, ou como desenvolvimento espe- 
rado, o progresso) sempre foi um dos móveis e, ao mesmo tempo, um dos resultados da pesquisa histórica.

As incertezas sobre o futuro, que se tornaram progressivamente mais agudas, em nível planetário, desde o último quartel do século XX, não poderiam assim deixar de projetar suas sombras sobre as maneiras como a História construía passados, com suas estruturas, suas leis, suas determinações, para projetar futuros já sabidos ou, no mínimo, intensamente almejados e tidos como possíveis. ${ }^{2}$ Aqueles passados tornaram-se anacrônicos e, muitas vezes, a pesquisa contemporânea parece correr o risco de enveredar pela nostalgia e pela angustiante defesa de um lugar no futuro para um passado (o que produz) que perdeu sua eficácia social como fator de compreensão e mudança. Ou talvez não! Apenas não encontrou um novo lugar para a História num mundo que se revela muito amplo e complexo para seus antigos quadros de referência. As maneiras pelas quais a História considera a história como seu objeto de estudo devem passar por mudanças drásticas. Vamos analisá-las em diferentes níveis: na definição mesma de história como objeto de estudo, nos recortes mais amplos que os historiadores produzem, suas grandes "unidades de sentido", nos conteúdos/narrativas com que preenchem esses recortes e, finalmente, nas relações entre tempo, estrutura e ação.

\section{A HISTÓRIA SEM RECORTES}

Faz parte dos pressupostos da disciplina que a história, em seu sentido mais geral, existe e pode ser objeto de conhecimento: ela é total e única, é "a" história da humanidade, noção que corresponde àquela, iluminista, da unidade do gênero humano. Um fóssil de homo sapiens sapiens de $150 \mathrm{mil}$ anos é, por exemplo, parte dessa história, a única história, que é a história do homem. No entanto, e até nossos dias, as Histórias Universais produzidas pela historiografia foram, de modo geral, Histórias particulares de certos ramos privilegiados da história, reproduzindo uma perspectiva cuja origem remonta à própria formação da disciplina a partir dos clássicos latinos e gregos. A historiografia européia, numa época em que só havia História científica na Europa, escreveu, desde meados do século XIX e em boa parte do século XX, a História do homem como história da civilização cristã ocidental e, embora menos abertamente, do processo de formação dos principais estados-nações europeus. Escreveu, assim, uma espécie de História Universal da Europa: daí a seqüência, que domina muitos currículos escolares, mesmo em países não 
europeus, que vai de uma História Antiga (dividida entre Oriente Próximo, Grécia e Roma), uma História Medieval, uma Moderna e assim por diante, correspondendo a "idades" essencialmente européias. Não se trata, obviamente, da História do Homem, mas de uma seqüência simbólica, apenas nocionalmente européia, pois não corresponde nem mesmo à história de qualquer parte específica do que se possa entender por Europa.

Esse viés eurocêntrico perpassou praticamente todas as interpretações mais globais da história incluindo aquelas de derivação marxista, que europeizavam o restante do globo (colocando suas histórias numa mesma seqüência de modos de produção) e definiam seu futuro comum (o socialismo) pelas transformações de um presente que era essencialmente europeu. O eurocentrismo da historiografia contemporânea é um claro viés, uma visão arbitrária e ideológica. Não precisamos rejeitá-lo com desprezo: afinal, toda interpretação da história é arbitrária e a História Universal européia, em certos termos, cumpriu um papel importante. Deu um primeiro sentido à história mundial, enquanto o presente e o futuro desta pareciam centrados na Europa, de onde partiam os impulsos para uma integração global. Mas hoje esse eurocentrismo é anacrônico e claramente insuficiente. Hoje é possível ver o desenrolar de histórias paralelas somando-se cada vez mais como parte de uma história só, ou melhor, no processo de tornar-se uma só, com a chamada globalização. Essa consciência despertada de que a História que estudávamos era apenas uma possibilidade entre muitas coloca desafios bem tangíveis à História contemporânea. Afinal, qual a relação entre a História e a história? É possível narrar uma única história ou devemos seguir apenas certos fios? Por que privilegiar o fio europeu? Quais outros podemos ou devemos integrar na narrativa? Tais questões são parte do desafio contemporâneo à História. Uma História Universal nunca foi tão possível e necessária. Como construí-la? Como falar do todo e também das partes? E quais partes? Quais novos critérios valorativos seriam apropriados para a escrita contemporânea da História? Não há, obviamente, uma resposta, mas a consciência do problema é, sem dúvida, um bom lugar para se principiar a pensar.

\section{OS GRANDES RECORTES DA HISTÓRIA}

A História, portanto, nunca se debruçou sobre a história humana como um todo, mas sobre histórias particulares, histórias de ALGO. Sempre estudou histórias específicas inseridas dentro de unidades de sentido (os ALGOS) 
que conferiam coerência a um corpo de documentos e a uma narrativa, descrição, explicação ou interpretação. Entender o modo como se definiram essas unidades, ou seja, os objetos particulares da História, é crucial para compreender os impasses contemporâneos da disciplina. Mas não é tarefa fácil! Tais unidades foram construídas como grandes objetos virtuais, grandes contextos, nos quais temas específicos podem adquirir sua razão de ser. Desde o século XIX algumas unidades maiores têm predominado como os grandes contextos da História: um povo, uma nação, uma civilização e, sobretudo, um estado-nacional, geralmente como termos coincidentes, ou cuja coincidência seria “desejável”. A História se repartiu, assim, por objetos que não são uniformes, nem equivalentes, e que mudam de abrangência ou de sentido de acordo com os interesses de quem financia, produz ou consome seus relatos.

A despeito das grandes mudanças pelas quais passou a disciplina nos últimos dois séculos, os historiadores ainda produzem suas Histórias dentro dessas unidades: fazem História da França, História do Brasil ou História da Cultura Ocidental, por exemplo. São estas as grandes unidades de sentido, os objetos por excelência da História, dentro dos quais se recortam temas específicos (a economia, a política, a sociedade e assim por diante) e que se projetam no passado, apropriando-se dele como sua memória, sua tradição, sua história. Mesmo Histórias mais remotas deixam-se contaminar por esses recortes, construindo-se uma História da "Grécia" antiga ou de "Roma", como se fossem nações da Antiguidade. Ainda hoje, por vezes, reparte-se o globo em "civilizações" distintas, com histórias diferentes, sem que se saiba ao certo o que é uma civilização.

Essas unidades recortam o passado no tempo, no espaço e culturalmente, como meios de conferir-lhe sentido. Ora, isso é inevitável e necessário. Mas esse procedimento nunca é inocente ou inócuo. Não importa quão científicas sejam, essas interpretações da História são sempre produtoras de memória, de lembrança ou esquecimento, são instrumentos de identidade, de legitimidade e de poder. Essas unidades de base tendem, além disso, a naturalizar-se, a adquirir existência própria, tornam-se pressupostos que não se discutem, como se fossem partes da "natureza" da história. O processo de fabricação de entidades como "povo", "raça" e "etnia" é hoje evidente, mas a mesma artificialidade afeta unidades como nação, estado-nacional e civilização. Como escrever a história de um estado-nacional sem projetar no passado sua definição contemporânea, suas fronteiras, a configuração de seu "povo"? Que se deve privilegiar: a história do Estado, a de um segmento de sua população, a do território contemporâneo? Não há, novamente, respostas fáceis. 
E o que dizer de civilização, termo tão em voga em certos debates políticos contemporâneos? Civilização não é um conceito, mas um termo visivelmente ideológico e propositalmente vago. Afinal, que é uma civilização? Opõese à barbárie, ao primitivo? Engloba todos os hábitos, crenças e costumes de uma sociedade, ou apenas aqueles mais "elevados", como a cultura literária e artística? Sociedades específicas correspondem a civilizações determinadas? Quais os limites, por exemplo, da chamada "civilização ocidental"? O que a define? O cristianismo católico ou protestante? A industrialização? O capitalismo? A sociedade civil de indivíduos iguais? O mercado? O termo é tão ambíguo e tão carregado de valorações contraditórias como as demais grandes unidades de que se vale o historiador.

Unidades de sentido como civilização ou mesmo nação são "formas" e não objetos concretos Normalmente, essas formas aparecem aos estudiosos como algo dado, como unidades quase naturais, dentro das quais escrevem suas Histórias específicas, sem perceber como essas formas pré-teóricas conformam nosso modo de ver o passado, abrem ou fecham campos de visibilidade, constroem, sub-repticiamente, o fio de uma história geral que nunca é abordada. Raramente se pensa sobre essas formas, mas é por meio delas que os historiadores reconstituem fatos e realidades e sobre as quais empregam suas eventuais teorias da história ou da sociedade. Tais formas, insisto, são parte necessária do trabalho de qualquer historiador. Se tentarmos pensar a história sem elas, teremos apenas uma sucessão de fatos desconexos, locais, particulares.

Se não é possível passar sem as formas, mas é necessário ter plena consciência de sua arbitrariedade, do modo como foram criadas e de como afetam nossas visões da História humana, não apenas para compreendermos os limites das reconstruções ou interpretações que propomos, mas também para termos a possibilidade de produzir visões alternativas, de criar ou escrever outros passados. E isso é necessário hoje, porque vivemos numa época de grandes transformações que exigem que reconstruamos nosso passado para torná-lo útil para o presente. O próprio presente nos impele a mudar a forma de ver o passado.

A História que produzimos em nossas universidades, por exemplo, ou aquela que domina nossos currículos escolares, ainda é uma História marcadamente eurocentrista, pois as formas européias tendem claramente a prevalecer: a idéia de nação é projetada no passado e estendida geograficamente; através de uma noção jamais explicitada de civilização incutem-se valores e identidades culturais, e assim por diante. Esta visão é ideológica e anacrôni- 
ca, centrando-se numa visão evolutiva da história que mantém ainda a Europa como o centro dos acontecimentos relevantes da história mundial. Como se o resto do globo, e nós incluídos, só passasse a ter história após o advento dos europeus. Ora, as transformações por que passa o mundo contemporâneo, notadamente a chamada globalização, que tende a unificar as histórias locais numa única, sob a égide do capital internacional e da expansão dos meios de comunicação, que afetam as antigas relações entre espaço e tempo que regiam as sociedades humanas, exige que tenhamos a capacidade de produzir uma visão mais global da história, para compreendermos, por exemplo, a diversidade do mundo de hoje, seus conflitos e suas perspectivas para o futuro.

O fato, no entanto, é que há, dentro da própria formação do historiador, uma espécie de força inercial, que dificulta uma reformulação mais radical das formas com as quais damos sentido à história humana. Os historiadores raramente ousam mexer nas formas, ou seja, nas unidades de sentido dentro das quais estudam e organizam sua documentação. Inventam outras teorias, buscam novos fatos, mas assumem as formas como naturais. $\mathrm{E}$ as formas acabam determinando suas interpretações de modo quase inconsciente, sobretudo nas interpretações de longo fôlego, mas mesmo no trabalho de formiga dos especialistas, contaminando, e deixando-se contaminar, com as demais formas presentes no universo cultural da nossa sociedade, em particular os currículos escolares. Alterar essas formas possibilitaria à História libertar-se de muitos de seus vícios de origem. Mas não é tarefa fácil. É propriamente dito "um impasse".

\section{OS CONTEÚDOS DA HISTÓRIA: ESTRUTURAS E TRANSFORMAÇÕES}

Os impasses da História contemporânea não se limitam, contudo, apenas a esses grandes contextos, essas imensas unidades invisíveis a que denominei "formas". Ora, foi sobre essas entidades quase naturais, quase eternas, que os historiadores projetaram seus objetos de estudo específicos, com suas diferentes formas de descrição e explicação e os diversos tipos de estrutura narrativa da História: dos fatos memoráveis, dos grandes personagens, dos processos e mudanças a serem descritos e explicados, por exemplo. Esses conteúdos específicos, no interior das formas, também são produtos particulares, que atenderam, em momentos distintos, a visões alternativas do que ver na história, de como pensá-la como movimento ou repetição. Desde o século 
XIX, mas mesmo antes, a própria idéia de uma história imóvel, reiterativa, voltada para o passado tornara-se progressivamente inviável. Era preciso explicar o movimento. Mas movimento de quê?

É verdade que algumas dessas grandes entidades/formas assumem por vezes um caráter quase permanente, como categorias imutáveis, antropológicas: povos e etnias têm seu gênio, seu caráter próprio, que é motor de seus destinos e realizações. Civilizações podem mover-se por um lento tempo "biológico", nascendo, crescendo e morrendo. Tais perspectivas, no entanto, logo caíram em desuso ou, se permaneceram, nunca foram predominantes. Desde cedo, os ramos centrais da historiografia, ao menos os mais influentes, procuraram explicações mais concretas e eficazes de mudança nas grandes formas, atuando em tempos mais precisos. Explicações que envolviam sempre o confronto entre uma dada estrutura (ou sistema, ou organismo) e um tipo ou vetor de ação. Seguindo uma direta influência dos historiadores greco-romanos e de alguns continuadores renascentistas, o tempo rápido da política e da guerra, movido pela ação de grandes líderes e generais ou por elites poderosas, e que era bem adaptado a Histórias de estados-nacionais, dominou as narrativas da História por longas décadas, já bem adentrado o século XX (e ainda não desapareceu).

A partir de meados do século XX fortaleceu-se uma tendência, que pouco a pouco predominaria (ao menos em certos países), a despersonalizar a ação transformadora e a cadenciar mais lentamente os ritmos de mudança, como forma de superar as limitações da velha história política e abrir-se para as contribuições da Sociologia, da Antropologia e da Economia e para a influência do marxismo. Povos, nações, estados, cederam um pouco o lugar no palco da História para agentes mais amplos, transnacionais, quase impessoais. Daí passaram a predominar, na escrita dos historiadores, as grandes estruturas sociais e econômicas, com seu próprio dinamismo e suas próprias determinações. $\mathrm{O}$ tempo e a forma da ação tornaram-se distintos: passaram às grandes ações coletivas, por vezes conscientes, mas quase sempre determinadas pelas próprias estruturas, com suas leis de transformação, que passaram para o primeiro plano da narrativa e tornaram-se os grandes agentes da história.

Um terceiro impasse da historiografia contemporânea liga-se, de modo evidente, à crise dessas grandes estruturas, isto é, dos conteúdos específicos que, nos últimos duzentos anos aplicaram-se às formas e davam sentido à sua mudança. Da política à sociedade e desta à economia, o espaço da ação humana tornou-se cada vez mais restrito, menos eficaz. A capacidade de projetar um futuro e de conceber o passado como sua origem e sua causa, como a 
explicação prévia de um projeto a se concretizar, esvaeceu-se nas últimas décadas. Algumas conseqüências dessa crise das grandes narrativas são: em primeiro lugar, os objetos da História se multiplicaram, não apenas pela introdução de novos atores sociais, cujas histórias se tornaram relevantes (trabalhadores, imigrantes, mulheres, homossexuais), mas pelo recurso cada vez mais intenso ao estudo de caso, ao detalhe, à micro-história que se esquiva dos grandes contextos sem conseguir negá-los inteiramente. Em segundo lugar, a duração temporal dos objetos da história tornou-se cada vez mais longa: da ação individual e pontual de grandes homens às explosões coletivas, à ação impessoal, cíclica, de efeito indeterminado das estruturas econômicas, ao tempo quase eterno e imutável das indefiníveis mentalidades. São apenas tendências, é verdade, e reconhecê-las como tais não nega a coexistência de diferentes concepções e modos de fazer História hoje. De qualquer modo, essas tendências parecem desembocar, nos últimos trinta anos, numa ênfase cada vez maior nos chamados estudos de história cultural.

\section{A CUlTura COMO CONTEÚdo DA HisTÓRIA}

A História cultural não é, certamente, uma especialização recente: quer a consideremos originária do século XVIII, com as reflexões de J. G. Herder sobre a Kulturgeschichte, depois significativamente desenvolvidas no final do século XIX e inícios do século XX por autores como J. Burckhardt ou J. Huizinga; ${ }^{3}$ quer a consideremos como uma especialização mais recente, da segunda metade do século XX, ${ }^{4}$ a História cultural contemporânea parece, em todo caso, derivar, não apenas do enfraquecimento dos antigos modelos interpretativos, das grandes estruturas da história, mas de uma maior aproximação da História com a Antropologia e com a Lingüística e, conseqüentemente, de uma maior consciência da imensa variedade e amplitude das sociedades humanas sobre a terra.

Mesmo hoje, quando parece tornar-se a tendência predominante, não é fácil definir História da Cultura como uma perspectiva única: a não ser por uma acentuada ênfase no caráter simbólico das relações humanas. A partir desse princípio, no entanto, pode estender-se da cultura popular ao mundo dos livros, ${ }^{5}$ do carnaval à cultura erudita, até chegar a esse universo amplo, vago, mal definido, compreendido sob o termo "mentalidades". De modo geral, a História da Cultura parece retornar aos tempos longos, quase naturais, aos tempos imóveis, nos quais a agência humana é, não apenas despersonali- 
zada, mas quase esvaziada de eficácia transformadora. A História que narra torna-se, por sua vez, mais intimista, mais detalhada, mais atenta para o indivíduo e sua vida privada, uma história longe da história e que, por sua vez, pretende por vezes dar conta de todas as dimensões da história. ${ }^{6}$

\section{Cultura e COTIDiano}

Dentre a grande diversidade dos estudos que podem ser classificados como de História cultural, aqueles dedicados à chamada História da Vida Privada ou História do Cotidiano ${ }^{7}$ apresentam uma característica particularmente relevante para avaliarmos os impasses da historiografia contemporânea. O gênero não é novo, remontando talvez à velha antiquística erudita que ainda competia com a História oficial em meados do século XIX ${ }^{8}$ (e reproduzia a antiga oposição entre Heródoto e Tucídides). Para além das intermináveis discussões sobre a pertinência do conceito para sociedades não européias, ou mesmo sobre a existência de "cotidiano", como instância própria e separada da vida (debates que afetam mais certos círculos sociológicos que propriamente históricos), é inegável que o crescente interesse pela História do cotidiano reflete um novo olhar sobre o indivíduo, sua ação e sua posição na história.

Curiosamente, o cotidiano aparece quase como o perfeito oposto da história, como o campo das estruturas permanentes, inconscientes, alienantes, quase naturais, sobre as quais as ações humanas são apenas banais, corriqueiras e sem efeito transformador. O cotidiano surge assim como refúgio da história, na insignificância banal do homem corriqueiro, dominado por estruturas que, ao contrário daquelas políticas, sociais, econômicas e, mesmo, culturais, de nada seriam dominantes, de nada seriam a causa eficiente. Trata-se de um limite, sem dúvida, de uma história sem história. Pela sua própria condição de limite, contudo, pode nos ajudar a pensar sobre o estatuto da história hoje. A visão que apresentamos de cotidiano é derivada do senso comum, mas reproduz, em grande medida, as reflexões a seu respeito nas ciências humanas.

Em termos bem gerais, os estudos sobre cotidiano tendem a valorizar, como foco de atenção, as ações individuais frente às circunstâncias da vida, sobretudo no plano da intersubjetividade. Para alguns, importam menos as "estruturas do cotidiano" que os tipos de ação observados em seu interior. Irving Goffmann enfatiza o cotidiano como espaço de interações humanas concretas, a partir de estratégias individuais de adoção e negociação de papéis so- 
ciais, predeterminados por uma instância estrutural que assume, na maior parte das vezes, o caráter de uma organização: os pequenos mundos do trabalho, dos hospitais, dos manicômios. ${ }^{9}$ Numa perspectiva fenomenológica, Alfred Schutz vê o cotidiano como "mundo de vida", essencialmente intersubjetivo, mas apenas perceptível na perspectiva de cada indivíduo, que se serve de um reservatório de 'conhecimento disponível” (de senso comum) que lhe permite agir sem duvidar, de modo espontâneo, trabalhando sobre as coisas e os demais indivíduos por atos de comunicação que podem ser automáticos ou performáticos, na medida em que visem uma situação projetada. ${ }^{10}$ Em ambos os casos, trata-se sempre de pequenos mundos, dominados por tipos específicos de pequenas ações rotineiras, mais que por estruturas específicas. Já H. Levebvre encara o cotidiano como um produto do capitalismo, como um espaço de alienação, de repetição, de imposição brutal das estruturas da vida sobre indivíduos inconscientes e incapazes de reagir e alterar seu mundo. Para Levebvre, ${ }^{11}$ como para seus seguidores, a "cotidianeidade", mais do que o cotidiano, representa a derrota da ação humana eficaz sobre a história. Para outros, como Michel de Certeau ${ }^{12}$ ou Michel Maffesolli ${ }^{13}$ (mesmo que a partir de premissas absolutamente diversas) a ação cotidiana é, pelo contrário, reação contra a unidimensionalidade do mundo, reivindicação do espaço e do valor da particularidade e da individualidade numa sociedade cada vez mais massificada.

Mais produtiva é a visão de Agnes Heller ${ }^{14}$ que, por sua vez, chama a atenção para as estruturas do cotidiano, o que considera "o mundo das objetivações”, dentro do qual se dão as ações cotidianas: a linguagem, o sistema de hábitos e o uso dos objetos e que representam o espaço de socialização dos homens, sobre o qual se acumula a cultura humana. Se é verdade que, para ela, essas objetivações possuem um caráter conservador e que o senso comum se reproduz de modo consuetudinário, através da repetição, do economismo, do pragmatismo, da imitação e da hiper-generalização, do cotidiano também podem surgir ações não cotidianas, criativas, inovadoras, sobretudo no campo das artes e das ações que quebram a rotina da vida. Essa perspectiva aproxima-se da de Claude Javeau e de sua tentativa de incluir, num único sistema de pensamento, a macro e a micro-história, um mundo de atores nunca solitários cuja ação coletiva, consciente ou não, produz e reproduz as instâncias da vida. Nesse âmbito, o próprio sentido de cotidiano, como instância à parte da vida, como o outro da história, parece esvanecer-se. ${ }^{15}$ 


\section{COTIDiAnO E História}

Os historiadores têm dedicado poucas reflexões ao tema do cotidiano e de seu lugar na História. O ponto de partida pode ser a famosa e sempre citada coleção da Editora Hachette, cuja "História antiquária" opunha-se em suas origens à grande História, àquela celebrativa, dos grandes feitos, das grandes estruturas, da guerra, da política, da luta de classes, da economia, em suma da História das causas eficientes da história. A História do cotidiano se apresentava, ali, como a História do banal, do corriqueiro, do dia-a-dia, da realidade rotineira na qual agimos de modo quase inconsciente e alienado. Um pedaço da vida em que nada aconteceria, a não ser o absolutamente previsível, no qual nada mudaria e que, no entanto, dominaria nossas vidas no que teriam de mais íntimo, individual, privado. Daí que tendia a ser uma História de viés antropológico, História dos hábitos e costumes de diferentes povos: o morar, o dormir, o trabalhar, o descansar, e assim por diante. Uma História de verbos substantivados. Sob esta visão, as esferas da vida privada eram organizadas numa espécie de tipologia da vida social que podia ser usada para qualquer sociedade, época ou lugar. Essa recompartimentação da História, quando foi empreendida, não deixou de ser interessante, a despeito de sua busca do exótico e de seu viés escapista. Representou uma reformulação radical do ângulo de visão do historiador comum (e da História comum) pela valorização da realidade "banal", da história de todos e de cada um, por oposição à grande História celebrativa dos grandes homens e dos grandes feitos. Mas, como já se notou, ${ }^{16}$ tinha limites evidentes: seus procedimentos típicos da velha antiquária: a busca do anedótico, de dados dispersos, de instantâneos agrupados numa tipologia da vida social que parecia como um figurino adaptável a qualquer época, sociedade ou lugar e fundada numa espécie de naturalização da sociedade e do homem, seu resíduo quase biológico: o dormir, o comer, o amar, o divertir-se. Uma História do não histórico.

Uma das raras tentativas de se abordar o cotidiano do ponto de vista da História é a de F. Braudel, seguindo um caminho sugerido por Marc Bloch. Não tanto aquele, mais conhecido, dos três tempos da história: o longo da geografia, o médio das estruturas econômicas e o curto dos acontecimentos; mas o Braudel historiador das "estruturas do cotidiano": a demografia, os alimentos essenciais, o luxo, a técnica, as unidades sociais. ${ }^{17}$ Tempos longos, estruturais, menos extensos que as determinações geográficas, porém mais estáveis que o universo das trocas. Tempos quase naturais dentro da economia das existências humanas. A visão de Braudel reforça a ligação entre cotidiano 
e tempo histórico, sem dúvida, mas talvez seja possível abordá-la de outras maneiras.

Uma releitura da visão braudeliana, riquíssima de sugestões, encontra-se no ensaio de F. Novais, ${ }^{18}$ que se apóia na concepção braudeliana, buscando naquelas estruturas mais gerais as condições concretas de sociabilidade, de ação social individual e coletiva. Em todo caso, por mais rica que seja de sugestões, a definição de Braudel mantém a separação clássica entre tempo do cotidiano (e da vida) e tempo do acontecimento (e da história) reproduzindo, no fundo, a tradicional distinção entre acontecimento histórico, prenhe de significado, e vida comum, repetitiva e estéril. Entre tempo das mudanças e tempo da reiteração, entre estruturas supra-dominantes e atores humanos que se dobram a injunções que não podem controlar.

Na Sociologia, na Filosofia, mesmo nas poucas incursões historiográficas, o cotidiano aparece, assim, ou como um tipo de ação, repetitivo e inconsciente, banal, ou como um espaço informe de interação, de percepção fenomenológica de si e do outro. Para o historiador, parece ser um conceito limite. Vincula-se ao tempo ${ }^{19}$ e parece negá-lo, como repetição, como não acontecimento, como eterna permanência do que no entanto sabemos, quase intuitivamente, que muda. Talvez seja útil pensarmos esse limite, levá-lo às suas últimas conseqüências, para investigarmos alguns dos impasses da historiografia contemporânea.

\section{COTIDIANO E TEMPO HISTÓRICO}

Tentemos pensar o cotidiano do ponto de vista de um historiador, ou seja, como instância temporal, mas tendo em vista que é preciso explicar duas realidades contrapostas e complementares: a permanência e a mudança ou, em outros termos, a relação entre estrutura e ação. Podemos conceber cotidiano a partir de dois ângulos. Em primeiro lugar, como uma dimensão propriamente temporal, como pura duração sem qualificações, o que é certamente arbitrário, mas servirá como exercício para, em segundo lugar, indagar o cotidiano como tempo qualitativo, investigando o que compõe esse tempo, de que é a duração. Talvez, realizado o exercício, possamos entender melhor nosso objeto, a história e as possibilidades de nossa ciência, a História.

Que é tempo cotidiano? Os historiadores têm, como vimos, a tendência a aproximar cotidiano e longa duração, como o tempo do não acontecimento. Talvez seja possível superar a falsa dicotomia entre cotidiano e história se pen- 
sarmos cotidiano não como tipos específicos de ação ou como uma dimensão particular, individualizada, das interações humanas, mas como tempo plenamente histórico, no sentido de ser tanto o tempo do "acontecimento" (no sentido tradicional) quanto do "não-acontecimento". Que é cotidiano? Na origem latina, quot dies é, ao mesmo tempo, um dia e todos os dias. ${ }^{20}$ Engloba, assim, tanto o instantâneo como o duradouro, o incisivo e transformador e o repetitivo. Cotidiano tem portanto dois sentidos temporais complementares. É o que acontece em um dado dia, num tempo brevíssimo, uma efeméride, e o que acontece todos os dias, portanto num tempo potencialmente longo. Ora, será essa dicotomia insuperável? Como se manifestam os grandes eventos, as grandes causas senão no dia, a cada dia, num dado dia? Não são eles também cotidianos? Não se produz a própria mudança no dia-a-dia, por meio de ações concretas, miúdas, seguidas, que se somam até tomar a forma de "acontecimentos"? "Pequenas" e "grandes" ações, o banal e o excepcional, a repetição e o único, a inércia e a transformação não existem em planos separados da existência, mas convivem, concretizam-se, no mesmo tempo comum da existência”, que é o cotidiano ou, como veremos, o presente.

O cotidiano, visto assim sem qualidades, como o tempo da vida, pode ser pensado como o espaço concreto de realização da história em todas as suas dimensões, a pública e a privada, a banal e a importante, a repetitiva e a transformadora. O cotidiano não é uma esfera particular da vida ou da história, ou uma espécie de massa inerte, que muda pouco ou não muda, pois não teria em si os agentes de sua mudança: uma massa sobre a qual os acontecimentos existiriam e atuariam de modo independente. Não há por que pensar a história como duas instâncias separadas: uma física, concreta, porém imóvel e inconsciente, em que todos vivemos, e outra metafísica, mas ativa, eficaz, de onde proviriam as ações que mudam, as forças da mudança. É verdade que acontecimentos singulares, ou antes, constelações de acontecimentos, de ações, podem alterar em maior ou menor profundidade aspectos de nossa vida, mas é no próprio tempo do cotidiano que são gerados. Eles se dão no tempo e no espaço do dia, na seqüência de dias. O acontecimento não é assim o inesperado, o imprevisto, não surge do nada, mas é um produto do cotidiano. Não há por que separar os dois planos ou, dito de outro modo, talvez seja útil pensá-los conjuntamente.

Daí que proponho ver o cotidiano não como uma esfera da vida, mas como um tempo, como um momento, um presente que, visto em perspectiva, congrega uma sucessão de presentes no fluxo contínuo da vida. ${ }^{21}$ Associar cotidiano a presente tem conseqüências importantes para o modo como enca- 
ramos a história. O presente que não é mera repetição do passado, mas um campo de restrições e possibilidades em aberto para projetos alternativos de futuro. O presente, entendido como o dia de hoje, é como o vértice de uma tríade temporal que forma, com passado e futuro, o curso da história.

Os historiadores tendem a esquecer o dia como unidade temporal da história. Não porque o dia seja desinteressante e fugaz, isento de acontecimentos (historiadores são, aliás, zelosos em datar acontecimentos num dia!), mas porque dia é tempo presente e os historiadores não costumam pensar essa dimensão do tempo - o presente. De modo geral, os historiadores ignoram em suas reconstruções ou explicações do passado o fato de lidarem com presentes. Na verdade, interpretam o passado por meio de futuros, empregando seu conhecimento do que aconteceu para explicar o que lhe sucedeu, como se cada passado visasse a um futuro, sem que um presente fosse o ponto necessário de ligação entre ambos. E um ponto no qual o futuro aparece ainda em toda a sua indeterminação e incerteza, como sonho, como projeto ou como angústia.

Invertendo as proposições de $\mathrm{H}$. Levebvre, o cotidiano, mesmo em nossos dias, é o tempo, não da alienação, mas do desejo e da angústia, da esperança e do medo. É uma perspectiva em aberto, não um destino manifesto, um resultado previsível e previsto. Ignorando essa dimensão da história vivida, a História dos historiadores é ainda marcadamente teleológica, seu método pode ser classificado como uma teleologia retrospectiva. É preciso inverter a perspectiva para pensar a eficácia das ações sociais individuais e coletivas. Não devemos considerar essa ênfase no presente apenas como um resultado negativo da recente opacidade com que o futuro se nos velou. Estudar o passado abrindo-se para as possibilidades em jogo a cada momento, avaliando os projetos alternativos e em conflito, sem privilegiar o vencedor, ou antes, sem valorizar unicamente o resultado indesejado de diferentes projetos, pode revivificar nossa visão do passado e fazer pensar sobre nossas possibilidades de projetar futuros no presente.

Visto por esse ângulo, como curtíssima e como longa duração, o cotidiano não tem duração, a não ser aquela que o historiador estabelece (voltaremos a este ponto). Mais que um fluxo contínuo de eventos, o cotidiano é uma ponte que liga passado e futuro, mas não de modo desordenado e caótico. Ao contrário, o presente só é vivenciável porque é previsível, porque é a reprodução de uma certa ordem ou, dito por outro ângulo, o próprio ato de reproduzir essa ordem (ou de não fazê-lo). No cotidiano se defrontam ordem e movimento, como uma só unidade, o que equivale a dizer, em termos socio- 
lógicos, estrutura e ação, que são as duas faces da permanência e da modificação, do passado e do futuro.

\section{COTIDIANO E TRABALHO MORTO: AS ESTRUTURAS DA VIDA}

Esses pares de termos são equivalentes, ou quase. O passado aparece no presente, na história, sempre na forma de trabalho morto, trabalho acumulado e transmitido pelo dia de ontem, que acumulou e recebeu o trabalho de dias anteriores, de anos, décadas, gerações. Na história humana, e talvez na biológica e mesmo na física, o tempo é trabalho, é acúmulo, é transmissão do acumulado. É assim que o passado parece dominar o presente. O passado se apresenta no presente concretamente, como massa potencialmente inerte $\mathrm{e}$ inercial, como trabalho morto com o qual cada um e todos nós precisamos nos defrontar. Algo produzido no ontem, no passado, na verdade em diferentes espessuras de passado, mas que só existe aqui e agora, no tempo presente, como uma "armação da vida". É passado, mas só existe no presente, influencia, ou mesmo, domina nossas vidas, mas só existe se for acolhido, aceito, reproduzido e transmitido para o futuro.

A semelhança com o conceito de trabalho morto, como Marx o via na composição do capital, não é simples coincidência. No processo produtivo, o trabalho morto se corporifica em máquinas, mas também em conhecimentos, técnicas, modos de fazer, circuitos de troca, que antecedem o processo de trabalho, mas que dele necessitam para ter existência concreta, para serem vivificados pelo trabalho vivo, concreto, atual, que os reproduz e transforma. $\mathrm{O}$ paralelismo com o trabalho morto do capital não é absurdo, é apenas a extensão de uma lógica que lhe é subjacente. Se aceitarmos a premissa de que toda ação é trabalho, é intervenção humana na sociedade e na natureza, e que o mundo social é produzido pelos homens e não imposto a eles por uma instância externa, metafísica, então a sociedade é o resultado desse trabalho, que é morto porque passado, mas é ativo, porque domina as ações atuais, direciona-as, define suas possibilidades.

O passado é, assim, a própria sociedade, o trabalho morto acumulado na história que cada um e todos precisam atualizar, reproduzir ou eventualmente modificar a cada dia segundo um determinado projeto de futuro, de amanhã. Mas o que se reproduz, para que se mantenha ou se transforme? Como dissemos, o trabalho morto que o passado transmite não é uma massa caótica, mas uma ordem, que simultaneamente permanece e muda. Que tipo de 
ordem? O que dá ordem à vida e à história. Não temos pretensão a responder. Há várias respostas possíveis, ou talvez não haja respostas. Aqui, propomos apenas alguns modos de ver, como meios para organizar o pensamento e pensar eventuais respostas. Optamos, conscientemente, por nos afastar de alguns pressupostos muito arraigados e arriscar um novo ângulo de visão. Pensar ordem sem separar corpo e alma, ou matéria e pensamento, nem classificar a existência social em dimensões estanques e quase autônomas: o econômico, o político, o social e o ideal, por exemplo. São vícios de pensamento, alguns dos quais remontam aos gregos, e é difícil libertarmo-nos deles.

A idéia de que o cotidiano é estruturado se impõe pela própria previsibilidade do presente. Entenda-se que o termo estrutura é empregado aqui em sentido propositalmente fraco e vago. Significa apenas que o trabalho morto que corporifica e atualiza o passado apresenta-se organizado, como totalidade sobre a qual se pode agir com previsibilidade. Estrutura e cognoscibilidade estão intimamente ligadas. As ações sociais que incidem sobre o trabalho morto têm resultados previsíveis porque o presente é cognoscível, mas este só é conhecido porque se atua nele. Não há por que separar estrutura e ação. Se o fazemos, aqui, é com fins analíticos.

A melhor tentativa de pensar essas estruturas é, a meu ver, a de Agnes Heller, que citamos anteriormente. Mas Heller pensa, sobretudo, no cotidiano como espaço de ações específicas, não como tempo que unifica estrutura e ação. Proponho vê-las de modo diverso, a partir de quatro ângulos incomuns, que não são complementares, nem dão conta da totalidade do objeto, nem se apresentam separadamente, nem estão no mesmo plano ontológico, mas que pretendem abarcar, à sua maneira, a totalidade da vida social. São aproximações ao trabalho morto, ao passado realizado, concretizado e reproduzido ou alterado a cada dia segundo projetos mais ou menos incisivos de futuro. São, no meu modo de entender, os fundamentos da ação social sobre o capital acumulado apresentado a cada dia pelo passado. Tendo consciência de que representam um recorte insólito da realidade social, proponho-as como peças para debate. São elas, em ordem decrescente de abstração: a memória; os juízos compartilhados, as inter-relações sociais e o mundo material. Não vou aqui descrevê-las ou discuti-las em detalhe, mas apresentá-las como peças de um debate. São circunscrições arbitrárias que procuram englobar o conjunto da vida social independentemente das teorias que procuram explicar o que seja sociedade. Forneço apenas traços essenciais, que permitam entender de que se trata em cada caso. ${ }^{22}$

Memória é a estrutura mais ampla e abrangente. É o próprio cimento da 
vida cotidiana. É, ao mesmo tempo, uma habilidade natural e uma construção social, uma atividade, um trabalho que dá sentido ao trabalho morto que compõe o palco da vida. A memória, individual ou coletiva, não é um repositório passivo, mas ativo, atuante, um imenso produto cultural. Memória é o vínculo, material ou ideal, entre passado e presente que permite manter as identidades a despeito do fluxo do tempo, que permite somar os dias de modo significativo. É ela que dá sentido ao presente. É essencial tanto para indivíduos como para a sociedade ou para grupos dentro dela. Seu contrário, a amnésia, tanto individual como social, corresponde à inação quase absoluta. Não existe ação que não seja calcada na memória. Mas memória não é apenas um recurso que possibilita a ação. É uma poderosa estrutura, um instrumento para o agir social e, portanto, uma fonte de poder.

São várias as formas da memória social, em diferentes sociedades. A escrita e o processo educacional são formas de memória, assim como a tradição erudita, livresca, a ciência, ou os relatos orais e as estórias que circulam entre grupos, os mitos, os heróis comuns e assim por diante. Memórias são produto de trabalho, são fabricadas. Mas são também acúmulos de trabalho morto que condicionam o presente ou permitem agir sobre este de modo decisivo, conferindo sentido à ação e identidade aos agentes. A memória, sendo fonte de poder, é também, inevitavelmente, um campo de batalha onde se defrontam interpretações do passado e do presente pelo passado, onde se criam e destroem identidades, tradições, símbolos, crenças, sentidos da vida que podem inibir ou estimular ações, individuais ou coletivas.

Juízos compartilhados designam as convenções sociais que tornam a vida pensável para determinados grupos, independentemente de suas dimensões: grandes, médios, mínimos. São espaços de comunicação e de negociação de sentidos. Compõem um conjunto complexo, não necessariamente coerente. Podem ser formalizados, como as leis, ou informais, como os costumes, podem ser consensuais, negociáveis ou pólos de tensão e conflito. O exemplo mais geral de um juízo compartilhado talvez sejam as línguas naturais, que podemos considerar uma convenção coletiva que permite a comunicação entre as pessoas, com todas as suas circunscrições e imposições. Outros exemplos abrangentes são as religiões, ou ainda os valores incutidos pelo processo educacional. O campo é muito vasto para o explorarmos em detalhe.

De qualquer modo, com toda sua complexidade, são eles que dão sentido às ações recíprocas, que estabelecem o espaço da normalidade, do esperável, do aceitável nas interações sociais. São mais do que regras impostas ou normas internalizadas. Formam um quadro comum para se interpretar e agir 
no mundo, definindo o que é normal e correto, o desejável e o possível (e seus opostos), seja para todos, seja para segmentos da sociedade. São sistemas de crenças e costumes mais ou menos arraigados, mais ou menos difundidos que permitem proferir juízos e julgar, aprovar ou condenar ações, prevê-las ou evitá-las. Invadem nossas vidas em todas as suas dimensões. Definem, para cada sociedade, e para cada grupo dentro dela, o que é, por exemplo, uma família apropriada: envolve casais de sexos distintos ou independe do sexo? Envolve filhos? Envolve mesmo casais? O que é sexo permitido e permissível? O que é amizade? O que é poder legítimo? Propriedade legítima? Ação legítima? Deus? Liberdade? Amor? O rol é infinito e multifacetado. O importante é ter em mente que não são definições naturais, mas culturais e que, portanto, não são eternas, nem consensuais. Mudam de sociedade para sociedade, época para época e grupo para grupo. Também são campo de negociação e conflito, de exercício do poder e mesmo de repressão violenta.

As interações sociais compõem uma dimensão extremamente complexa e estratificada que engloba a maior parte daquilo que os sociólogos costumam denominar de organização social, ou seja, das obrigações que vinculam indivíduos ou grupos específicos uns aos outros, dentro de uma determinada totalidade social. Talvez se possa pensá-las conjuntamente como relações de troca, em termos grosseiramente genéricos, na medida em que toda relação pode ser concebida como troca entre indivíduos ou grupos, na produção, no círculo profissional ou de amigos, na família, na rede de vizinhança, relações que se interpenetram de maneiras diferentes em sociedades diferentes. É a dimensão na qual as pessoas se organizam para e por entrarem em contato, na qual trocam bens, idéias, serviços, se auxiliam, exercem poder ou obedecem, se exploram, produzem, se unem e diferenciam, são indivíduos sedes de redes, são grupos dentro de uma sociedade, são coletividades num mundo de sociedades contrastantes. As redes de relações programam e definem as ações cotidianas de indivíduos e grupos. São ações cristalizadas em expectativas de reprodução, são trabalho morto cuja reprodução e/ou transformação corresponde à da própria organização social.

Já o mundo material engloba tanto a natureza como meio, quanto a parcela da natureza apropriada e transformada pelo homem, que dá forma ao mundo, conforma o palco da vida, representando trabalho humano concretizado, materializado como trabalho morto. Não é um meio simplesmente passivo, mas uma realidade instituída e construída, que conforma nossa vida, define nossa percepção do entorno e fornece a estrutura física da vida cotidiana (propicia atividades sociais, os espaços e meios delas) dando-lhe estabilidade, 
identidade e previsibilidade. Como mundo transformado, na forma de estruturas e objetos, que devem ser produzidos e podem ser trocados, acumulados, usados, representa um capital acumulado que dá forma ao mundo e espacializa, concretizando, as demais estruturas cotidianas. Nesse sentido, também é um instrumento de poder, tanto sobre a natureza quanto sobre homens, meio de luta e de dominação. Os objetos, o mundo material, são instrumentos significativos e simbólicos, que unem e diferenciam: sexo, idade, grupo ou classe, prestígio social, poder, honra, dignidade e preferências como consumidor, por exemplo. Como as demais estruturas, o mundo material é trabalho acumulado, passado, morto, que se apresenta a cada dia como limitante à ação, mas também como campo de possibilidades, como espaço de negociação.

\section{TRABALHO MORTO E AÇÃO: PERMANÊNCIA E TRANSFORMAÇÃO}

As estruturas do cotidiano, tal como já as definimos brevemente, são uma abstração, um produto do pensamento. Não existem separadamente na vida real, que é una. São antes modos de ver, de analisar essa realidade cuja estrutura é unitária. Mais que isso, são divisões arbitrárias de um todo que engloba estrutura e ação. São, como dissemos, ações condensadas, ações passadas, sobre as quais se exerce a ação presente. Além disso, tal como apresentadas, são unidades pretensamente homogêneas e extensivas, encobrindo uma imensa gama de subdivisões: de memórias distintas, estanques ou conflitantes; de juízos grupais, setoriais ou mesmo excêntricos; da tensão graduada entre coletivo(s) e indivíduo(s), que beira o paradoxo (a ação coletiva passada, o trabalho morto, domina a ação individual, mas não é senão soma de ações individuais); das múltiplas leituras possíveis do mundo material. São, assim, um recorte da realidade propositalmente mediano para dar conta tanto das totalidades sociais quanto do mundo miúdo das vivências particulares.

Essas estruturas do cotidiano são produtos coletivos, soma de inumeráveis atos individuais, que condensam o trabalho passado realizando-o a cada instante, a cada dia, a cada ciclo. São o produto, talvez aleatório, de ações particulares, mas não são caóticos. Indeterminação do futuro não equivale à desorganização do presente que se torna passado. O passado, sobretudo, é organizado. É a ele, ao passado, que denominamos "organização social", "realidade social", "fato social". O passado é não apenas organizado, mas previsível, e as 
estruturas propostas visam precisamente pensar essa organização e previsibilidade.

Essas estruturas não existem em si, mas apenas na medida em que são reiteradas, negociadas, pressionadas, alteradas no espaço de cada dia, a cada dia. São, ao mesmo tempo, indutores e inibidores da ação social, campo do necessário, mas também do possível, passado a se tornar futuro pela ação presente. Vista desse modo, a realidade social aparece sob nova luz. Nem a ação individual de grandes homens, nem a força de acontecimentos únicos que irrompem inesperados na história, nem o movimento lento, cego e inexorável de estruturas anônimas e impessoais. A história e a vida voltam a ser ação humana sobre a realidade e ressurge a possibilidade de "mudar o rumo" da vida, de "fazer história", ainda que inconscientemente, ou que, apenas, pela soma mais ou menos aleatória de atos e vontades individuais.

Pensemos mais detidamente sobre a relação entre estrutura e ação no tempo da história. O que denominamos passado no presente, trabalho morto, parece dominar a vida, determiná-la. O passado existe apenas como trabalho morto que precisa ser reproduzido a cada dia, e o futuro como projeto de reprodução e/ou transformação. O passado aparece como dado, como realidade preexistente com a qual temos que lidar. Por um lado, esse trabalho morto, acumulado, com o qual nos defrontamos a cada dia, é positivo: representa um capital acumulado por gerações (conhecimento, domínio da natureza, capacidade produtiva e intelectual, círculo de relações que animam nossa vida, por exemplo), representa um universo de previsibilidade que torna a vida possível de ser vivida. É necessário que o aceitemos para podermos continuar a viver. Desta forma, ele precisa ser reproduzido, a cada dia, ou ciclo de dias, para que a vida continue a fazer sentido e seja "vivível". A tendência, que vimos ser generalizada, de associar cotidiano a um tipo de ação repetitiva e banal reflete, precisamente, embora de forma unilateral, a necessidade de reproduzir o passado para viver o presente: seja a reprodução imediata, seja a cíclica. $\mathrm{O}$ ato de reproduzir o trabalho acumulado, que é precisamente o que denominamos cotidiano, é comumente cadenciado por ciclos, que não são a "duração" do cotidiano, mas seus ritmos, tanto naturais como humanos. $\mathrm{O}$ ciclo básico e mínimo talvez seja, como sugere a palavra, o espaço de um dia: o dia solar. Não é um espaço fixo, como sabemos, mas variável no tempo e no espaço. Um dia podem ser seis meses, isto é, 180 outros dias. Se a reprodução sempre se concretiza no dia-a-dia, a cada dia, pode ter momentos, ou ciclos, diferenciados: pode ser semanal, semestral, anual, sazonal, natural, cultural, social ou econômica, por exemplo. Há, assim, vários ciclos de reprodução e 
reiteração da vida social, eles fazem parte do cotidiano e de seu universo de expectativas.

Mas a ação cotidiana, a ação que se exerce sobre a massa inerte do passado, sobre o trabalho morto, não é apenas ação reiterativa, reprodutiva. O passado não determina o presente de modo absoluto. Em primeiro lugar porque toda reprodução é, também, transformação. $\mathrm{O}$ ato reiterativo é antes um desejo ou uma necessidade de manutenção da ordem que a cristalização eficaz do presente num eterno passado sem futuro. $O$ trabalho se acumula, o trabalho acumulado muda de forma, as relações se alteram, em suma, nenhuma ação reprodutiva é plenamente eficaz.

Porém, o passado não é só limitação, é campo de possibilidades, cada vez mais amplo, mais rico. E sua ordem, se é condição de existência, não representa necessariamente (muito pelo contrário) aceitação da herança como fardo e como destino. O passado/trabalho morto é também fonte de insatisfações, de imperfeições, de crises, de desarranjos. É possibilidade de vida social, mas também dos conflitos internos a essa vida. Tem seu lado claro, luminoso, de realização, mas não esconde sua face mais escura, de miséria, exploração, violência, dor. Isso é verdade em termos individuais (em casa, no trabalho, na rotina massacrante, na humilhação e na miséria, por exemplo) e coletivos (na exploração, no racismo, na dominação de classes e na violência). Sobre a massa do trabalho morto que o passado apresenta, as ações humanas como que flutuam, com uma liberdade contida. Nem tudo pode ser mudado, sem que a possibilidade da vida social desapareça, mas nem tudo precisa ou deve permanecer como está. Os homens reproduzem suas vidas no dia-a-dia, mas nunca da mesma maneira, e projetam mudanças no cotidiano e para o cotidiano, para que este se altere.

A vida é uma soma de atos reprodutivos do passado e de atos transformadores, automáticos ou involuntários ou mesmo organizados e associados a projetos de futuro. Reproduzimos o que queremos ou o que somos obrigados a reproduzir e transformamos o que queremos ou o que temos forças para transformar, individualmente ou em conjunto. Nossa capacidade de mudar a realidade é variável. Pequenas decisões podem mudar o curso de vidas individuais. Grandes transformações dependem de ações públicas, coletivas, que são o somatório de ações individuais, coordenadas ou não. O cotidiano é um bom ângulo para pensarmos a eficácia da ação humana e suas modalidades, da individual à coletiva, da organizada à aleatória, da desejada à involuntária, da consciente à intuitiva.

O presente, em suma, aparece-nos como dado, como estruturado inde- 
pendentemente de nossa vontade, como trabalho morto, que devemos aceitar ou não, reproduzir ou não, a cada dia, ou a cada ciclo de dias. Essa estrutura, esse trabalho morto que é prévio a toda ação, determina todas as ações. É, ao mesmo tempo, uma possibilidade, a base de qualquer ação, os meios materiais e mentais concretos para realizá-la e uma constrição, na medida em que condiciona a ação, limita-a, tende a reproduzir-se e a impedir a mudança. Mas não é uma camisa de força, porque os indivíduos e/ou grupos permanentemente confrontam-se com ela, negociam-na, alteram-na. As estruturas do cotidiano são também espaços/palcos de conflitos, podendo ser consensuais ou apenas hegemônicos, ou mesmo claramente conflituosos.

Parece-nos, portanto, possível e necessário redefinir o modo como a historiografia contemporânea encara três elementos centrais em suas narrativas: sua perspectiva temporal e a relação entre estrutura e ação. Apenas do ponto de vista da história, com efeito, estrutura e ação aparecem, não como dois termos distintos e contrapostos, mas como um processo, que só se dá no tempo e pelo tempo, de reiteração ou transformação de ações humanas num fluxo que parece contínuo.

A continuidade desse fluxo será nosso último problema e, talvez, o mais crucial de todos. A grande virtude da História, no âmbito das Ciências Humanas, é sua relação particular com o tempo. Não apenas no sentido mais óbvio, de poder aplicar, ou testar idéias, teorias, modos de ver produzidos pelas outras Ciências Humanas, ${ }^{23}$ nem por aquele, talvez mais importante, de revelar realidades empíricas já desaparecidas, para pô-las em confronto e relacioná-las com o presente, mas também aquela, toda particular, que é a de trabalhar sobre um objeto em movimento. Um objeto que a História precisa, ao mesmo tempo, artificialmente congelar, como ALGO passível de estudo, mas de cuja dinâmica, de cujas transformações não pode fugir: ao contrário, deve considerá-las o foco de sua atenção. Para a História, mais que para outras disciplinas, estrutura e ação aparecem como uma unidade, como duas maneiras de se descrever o que, na verdade, é um processo. Um processo que só se estuda como um ALGO, através de recortes, seja determinando períodos, nos quais o ALGO quase se congela como objeto, seja recortando espaços dentro desse ALGO: grupos de bairro ou conjuntos de crentes, sociedades pequenas e grandes, unidades políticas, economias nacionais e assim por diante. Recortes são arbitrários, mas necessários. E esse é talvez o maior dos desafios da História contemporânea: refazer seus recortes tradicionais, pois eles não mais dão conta da realidade. Porque podemos ver, hoje, como sua pretensa "naturalidade" era artificial. 
Começamos este artigo, com efeito, criticando as velhas subdivisões da história e alertando para seu caráter eurocêntrico e anacrônico. De que modo uma História, vista pelo ângulo do cotidiano, pode contribuir para renovar aquelas velhas formas? A resposta não é simples. Como vimos, as "estruturas" que, tentativamente, impusemos à história para explicar sua ordem e suas mudanças não correspondem aos recortes tradicionais com os quais trabalha o historiador, nem em termos das unidades de estudo, nem em termos das "forças" que estruturam ou põem em movimento as mesmas unidades. Por sua vez, as estruturas que propusemos, de modo indicativo, tampouco são complementares ou hierarquizadas. Não formam, em suma, unidades em si, que pudessem ser assumidas como tais pela História. Apenas à guisa de exemplo: um mesmo espaço lingüístico não precisa coincidir com um conjunto de tradições literárias ou artísticas; uma memória grupal, ou nacional, não corresponde necessariamente a uma dada rede de interações sociais, uma estrutura de poder não equivale a um circuito de produção, troca e acumulação de bens. Não há um único cotidiano definido pelas quatro estruturas, nem mesmo no mundo cada vez mais unificado em que vivemos. Não existe uma sociedade capitalista, um mundo industrial, uma sociedade civil, nem mesmo a sociedade de um país. Mas é verdade que para pensar o mundo precisamos ainda de recortes, necessitamos identificar ou propor diferentes cotidianos, que façam sentido em diferentes círculos de reprodução e transformação da vida. A historiografia contemporânea vem, pouco a pouco, atentando para a possibilidade de trabalhar com novos recortes, recusando-se a aceitar as unidades "naturais" transmitidas pela tradição da disciplina e procurando ver como, na vida concreta das sociedades, tais recortes são construídos, como identidades são fabricadas ou desfeitas, como grupos humanos se aproximam ou se afastam construindo memórias comuns ou distintas, organizando-se e dispersando-se, compartilhando ou contestando valores cruciais, agrupando-se para agir, ou conformando-se com a inação, estabelecendo ou contestando relações de produção e de propriedade. De qualquer modo, o historiador não escapará jamais da necessidade de impor seus próprios recortes ao passado. $\mathrm{O}$ que não pode mais fazer é tratá-los como objetos naturais.

Num certo sentido, assistimos, nas últimas décadas, ao fim da História. Não, obviamente, ao término da história das sociedades humanas, mas ao fim da possibilidade de se escrever História como se fazia até então, uma História européia, delineada por interesses localizados, mesmo quando se pretendia universal. Os objetos "naturais" que produziu e estudou estão se esvaindo com o tempo, pelo próprio processo de sua reprodução e transformação. O que se 
denominava, há algumas décadas, como a fragmentação da História, era uma falsa crise, era sim uma mudança interna e salutar. Representava a multiplicação dos centros de estudos pelo globo, a identificação de novos estoques documentais, de novos problemas, de novos recortes possíveis. Mas ainda era uma fragmentação européia e, por isso, insuficiente. É preciso recortar novos objetos, em novas escalas, e isso só uma História mundializada pode fazer. Só uma História mundial, ciente da unidade da história, pode dar conta da imensa variedade e diversidade das histórias da história humana.

\section{NOTAS}

${ }^{1}$ Para efeito de maior clareza, História (com H maiúsculo) representará, ao longo deste artigo, a disciplina científica, enquanto história (com h minúsculo) será empregado no sentido da história real, vivida.

${ }^{2}$ Entre inúmeros outros veja-se FONTANA, J. História: análise do passado e projeto social. Bauru/SP: Edusc, 1998, passim e particularmente p.264ss. Interessante a idéia de que ingressamos num novo "regime de historicidade" inaugurado a partir de 1989 em HARTOG, F. Tempo, História e Escrita da História: a Ordem do Tempo, Revista de História, n.148, 2003, p.9-34. A valorização do presente, no entanto, não é necessariamente negativa, vejase FONTANA, J. La Historia después del fin de la Historia. Barcelona: Grijalbo, 1992, p.143, retomando Benjamin na sua idéia de "atualização" da História. Uma boa introdução às discussões contemporâneas encontra-se na coletânea editada por JENKINS, K., The Postmodern history reader. London/New York: Routledge, 1997. As discussões sobre a cientificidade da História, na esteira de um $\mathrm{H}$. White, não nos interessarão aqui, pois estão largamente superadas.

${ }^{3}$ KELLEY, D. R. El giro cultural en la investigación histórica, in: OLABARRI, I. \& CASPITEGUI, F. J. La "nueva" historia cultural: la influencia del posestructuralismo y el auge de la interdisciplinariedad. Madrid: Ed. Complutense, 1996, p.37ss.

${ }^{4}$ Um "cultural turn" correspondendo ao famoso "linguistic turn"; veja-se HUNT, L. A nova história cultural. São Paulo: Martins Fontes, 1992, e, para uma apreciação crítica da "virada" como tal CARDOSO, C. F. Introdução: uma opinião sobre as representações sociais, in: CARDOSO, C. F. \& MALERBA, J. (Org.) Representações: contribuição a um debate transdisciplinar. Rio de Janeiro: Papirus, 2000.

${ }^{5}$ CHARTIER, R. La Historia hoy en dia, dudas, desafios, propuestas. In: OLABARRI, I. \& CASPITEGUI, F. J., op. cit., 1996, p.27.

${ }^{6}$ CHARTIER, R., op. cit., 1996, p.29, criticado por CARDOSO, C. F., op. cit., p.11-20. Cf. CASTRO, H. História Social. In: CARDOSO, C. F. \& VAINFAS, R. (Org.) Domínios da His- 
tória. Rio de Janeiro: Campus, 1997, p.50-4, para quem a antiga história social desembocou, inevitavelmente, numa história cultural das relações sociais e do poder.

${ }^{7}$ Embora não representem exatamente o mesmo objeto, os termos têm sido considerados como quase equivalentes pela historiografia. Cf. NOVAIS, F. A. Condições da Privacidade na Colônia. In: MELLO E SOUZA (Org.) História da vida privada no Brasil. Cotidiano e vida privada na América portuguesa. São Paulo: Companhia das Letras, 1997, p.17; DEL PRIORE, M. História do cotidiano e da vida privada. In: CARDOSO, C. F. \& VAINFAS, R., op. cit., 1997, p. 259-74; VAINFAS, R. História da vida privada: dilemas, paradigmas, escalas. Anais do Museu Paulista, n.4, 1996, p.14-6; LE GOFF, J. A História do cotidiano. In: História e Nova História. 2.ed. Lisboa: Teorema, 1989, p.73-82. Contra essas posições cf. MARTINS, J. de S. Apontamentos sobre vida cotidiana e História, Anais do Museu Paulista, n.4, 1996, p.49-58.

${ }^{8}$ MOMIGLIANO, A. Origines des recherches sur l'antiquité. In: Les Fondations du Savoir historique. Paris: Belles Lettres, 1992, p.61-91.

${ }^{9}$ GOFFMANN, E. La presentacion de la persona en la vida cotidiana. Buenos Aires: Amorrurtu, 1959.

${ }^{10}$ SCHUTZ, A. Le Chercheur et le quotidien, Ch. IV: Sur les realités multiples. Paris: Méridien Klincksieck, 1987, p.103-29.

${ }^{11}$ LEVEBVRE, H. Critique de la vie quotidienne. I. Introduction. Paris: L Arché, 1958. Para uma defesa enfática, mas não muito consistente, do autor ver MARTINS, J. de S., op. cit.

${ }^{12}$ CERTEAU, M. L'invention du cotidien. 1. arts de faire. Paris: Gallimard, 1980. Particularmente interessante sua noção de estratégia e de resistência.

${ }^{13}$ MAFFESOLI, M. A Conquista do presente. Rio de Janeiro: Rocco, 1984.

${ }^{14}$ HELLER, A. Sociologia de la vida cotidiana. Barcelona: Ed. 62, 1977 (1970).

${ }^{15}$ JAVEAU, Cl. La société au jour le jour. Écrits sur la vie cotidienne. Bruxelles: De BoeckWesmael, 1991, em particular p.82ss.

${ }^{16}$ DUBY, G. Prefácio. In: VEYNE, P. (Org.) História da vida privada: do Império Romano ao ano mil. São Paulo: Companhia das Letras, 1992, p.10; LE GOFF, J. A História do cotidiano, op. cit., p.79.

${ }^{17}$ Para as primeiras concepções de Braudel sobre a longa duração, ver BRAUDEL, F. História e Ciências Sociais: a longa duração. In: Ensaios sobre a História. São Paulo: Perspectiva, 1978. Fundamental é BRAUDEL, F. Civilisation matérielle, économie et capitalisme. XV-XVIII, em especial o v.1. Paris: Collins, 1967. Ver os comentários pertinentes de PENALVES, A. Tempo histórico e civilização material,. In: LOPES, M. A. Fernand Braudel. Rio de Janeiro: FGV, 2003, p.21-34. Impossível concordar plenamente com REIS, J. C. Nouvelle histoire e tempo histórico: a contribuição de Febvre, Bloch e Braudel. São Paulo: Ática, 1994. 
${ }^{18}$ NOVAIS, F. Condições da privacidade na Colônia, op. cit., p.14-39.

${ }^{19}$ VAINFAS, R. História da vida privada: dilemas, paradigmas, escalas, op. cit., p.19: "cotidiano é conceito que diz respeito ao tempo, sobretudo ao tempo longo".

${ }^{20}$ SISSA, G. \& DETIENNE, M. Os deuses gregos. São Paulo: Companhia das Letras, 1990, p.17; Para os gregos, segundo os autores: "a humanidade é marcada, estigmatizada mesmo pela noção de dia, de tempo breve, de tempo instantâneo", "Aos homens, aos mortais, toca, portanto, a cotidianidade, a força vital de curta duração, enquanto os deuses guardam para si o 'sempre".

${ }^{21}$ FONTANA, J.. La Historia después del fin de la Historia, op. cit., p.13.

${ }^{22}$ Não há, obviamente, bibliografia sobre essas estruturas como aqui apresentadas.

${ }^{23}$ Sobre as relações entre História e Ciências Humanas vejam-se as interessantes observações de FONTANA, J., La Historia después del fin de la Historia, op. cit., p.81. 